\title{
Preliminary Studies on Number of Coil Turns per Phase and Distance between the Magnet Pairs for AFPM Ironless Electricity Generator
}

\author{
Yap Wee Leong ${ }^{1,}$, , Akhtar Razul Razali ${ }^{1}$, Gigih Priyandoko ${ }^{1}$ and Nazrul Idzham Kasim² \\ ${ }^{1}$ Faculty of Mechanical Engineering, Universiti Malaysia Pahang, Malaysia \\ ${ }^{2}$ International College of Automotive (ICAM), Malaysia
}

\begin{abstract}
The generator that normally used in the market, which is the iron-cored electricity generator has high cogging and starting torques. By redesigning of the iron-cored electricity generator, Axial-flux Permanent Magnet (AFPM) configuration minimizes the usage of ferrite material. AFPM, one of the coreless electricity generator configuration has a less counter electromotive force (CEMF) compare to the cored electricity generator. AFPM configuration also has no cogging torque and low starting torque. Application of a coreless electricity generator is the most suitable compare to the cored electricity generator. However, it is expected that the elimination of the ferrite material within the coreless electricity generator itself increases the power generation. The configuration is the ironless electricity generator. This paper presents the design and analysis of the AFPM ironless electricity generator. There are two main parameters present in this paper, different number of turns of coil per phase and distance between a pair of the magnet. The result of the analysis shows that when the coil turns per phase increased, the voltage output and magnetic flux within the coil also increased. While increasing the distance between the magnets, the voltage output, and magnetic flux within the coil decreases.
\end{abstract}

\section{Introduction}

The iron cored generator is a type of the generator that widely used in the market. The usage of ferrite material on the iron-cored generator makes the generator itself become less efficient because of its high starting and cogging torques. The coreless electricity generator [1], the redesigning of the iron-cored generator by minimizing the usage of ferrite material on the generator itself, is seen as a promising solution to capture energy during in motion. Compare to the iron-cored electricity generator, coreless electricity generator had much lower cogging torque because of the elimination of the most ferrite material within the generator itself. However, compare to the ironless electricity generator, it has much lower starting torque, higher efficiency and can produce a considerable amount of electricity based on the size of the generator itself. This type of generator has no cogging effect and low CEMF resistance [2] during the operation to produce the electricity. It is because the generator itself does not have the iron core lamination that can be found in the iron-cored and coreless electricity generator. The iron-cored used in the cored system causes magnetic field between the iron-cored and the permanent magnet to resist the motion and thus, increase the starting torque and cause unnecessary loss of the electricity generated. The ironless electricity generator, the design that

\footnotetext{
${ }^{\mathrm{a}}$ Corresponding author: weeleong99@hotmail.com
}

eliminate the usage of ferrite on the generator can further decrease the starting torque and unnecessary losses. From there, the ironless electricity generator is a promising solution to overcome issues faced by the iron-cored generator.

\section{Background Studies}

It is divided into 5 sections. For section 2.1, the discussion on electricity generator is made. While in section 2.2, it discusses the magnet used in electricity generator. For section 2.3, the discussion on the coil winding, in section 2.4, it discusses the gaps between the magnets and for the section 2.5 , it concludes the literature review.

\subsection{Electricity Generator}

Since the coreless electricity generator had no cogging torque and low starting torque, it is suitable to apply to the wind turbine. It is because there is no iron used in the stator construction and this in turns avoids direct magnetic attraction between rotor and stator [3].

For the AFPM machine, it is a type of coreless generator configuration. It has less core material than the iron-cored configuration. Moreover, AFPM machine has 
thin magnets, means that smaller than radial-flux counterparts [4]. The proposed generator had maximum efficiency at the rated operating conditions is $96.6 \%$ as compared to the value of $95.7 \%$ of the model of AFPM generator [5]. Compare to Radial Flux Permanent Magnet (RFPM), AFPM has a smaller volume and lower mass with the same power rating. [3].

For AFPM generator, it is made up of 2 different parts, namely rotor and stator. There are five various types of combination for coreless type generator, a double-stator slotted type, a double-rotor slotted type, a single-sided axial flux permanent magnet with stator balance, a singlesided axial flux permanent magnet with rotor balance and a slotless single-stator double-rotor type. Two-sided axial flux permanent magnet type is better than one-sided axial flux permanent magnet [6]. It is because of its high compactness, and disk-shaped profile makes the model suitable for integration with mechanical components such as wind turbine and internal combustion engine [7] and an additional generator for hybrid vehicles. This type of generator has no core and always has low inductance and thus, the increasing of current does not affect the machine performance [8]. It is cheap, easy to manufacture, and can produce up to hundreds of kilowatts of power in multidisk operation. [9-10]. This type of generator also can operate on a wide variable range of frequency for optimal operation as well as provides an option to use the a gearless operation [11].

For the iron-core type inductors or iron-core type generator, it has high electricity conductivity due to the usage of iron in the lamination of the core. Thus, the main inductance decreases [12].

Because of the compactness and lightness as well as their high efficiency of the axial-flux coreless machine, they are among the most suitable candidates for many automotive applications [13]. It is because of the absence of core loss that caused by the iron core itself, the coreless stator AFPM machine can operate with higher efficiency compared to the conventional iron core machines [14].

The permanent magnet configuration is gaining a reputation amongst the researchers because of their highpower density, high torque-to-inertia ratio, high efficiency [15-16] as well as their robustness [17]. A special characteristic of the axial-flux coreless permanent-magnet generator is the usage of the nonferromagnetic holder to counteract the centrifugal forces acting on the magnet during the rotation of the rotor disks [18]. The coreless configuration of axial flux machine eliminates ferromagnetic material. Thus, it eliminates the eddy current and hysteresis losses in the generator. It can stack axially so that the mechanical construction of the coreless axial flux machine can be simplified, reduced the weight of the stator so that small size actuator can employ for winding shift [19]. However, the usage of the back iron core in the design did not totally eliminate the cogging torque since the iron somehow reacts with the electromotive force during operation.

The output differs with the different number of poles and magnet strength [20]. In the Kobayashi's research, they found out that 48 poles generate most magnetic fields compared to 12 poles and 72 poles. The increase of poles number, the size of the coreless electricity generator also increased. For the large pole number, the diameter of the magnets and coils are fixed and limit the radial length of the active area that makes the generator has large radius with small active length. While for the small pole number, low-power turbines tend to spin relatively fast, but as power increases, reduction in speed is required, the number of poles should increase. The radial length of the active area can be small compared to the radius of the stator. This kind of problem can be reduced by using trapezoidal or rectangular magnets, and active length can decouple from each other [21].

\subsection{Magnets}

Since the magnet carries a significant role in making the generator an efficient one, the choice of making choose of magnet need to consider well. Neodymium Iron Boron $(\mathrm{NdFeB})$ magnets are well known as the best magnet to be used. The continuous progress in the new high magnetic field rare-earth permanent magnets such as $\mathrm{NdFeB}$ magnet has given the automotive sector excellent opportunities on novel topologies for electric machine [22]. Increased availability and decreasing cost of highenergy permanent magnet materials, which is Neodymium Iron Boron $(\mathrm{NdFeB})$ magnet, has resulted in rapid, permanent magnet generator development [23]. This modern magnetic material can easily obtain in the market with different shapes and grades. Thus, the design of the usage for magnet can be done easily. There is operating temperature within the magnet itself. Below the maximum operating temperature of the magnet, the magnet works perfectly fine, which is full magnetization, can be achieved. However, when the temperature exceeds maximum operating temperature, the magnetic force depleted until it reaches the Curie temperature, the magnet totally lost its magnetic force. When talking about the operating temperature of the magnet, it is closely related to the Permeance Coefficient of the magnet. Permeance Coefficient is the method of calculation to measure the shape of magnet since the maximum operating temperature differs from the shape of the magnets. The Permeance Coefficient is higher if the magnet has long and small cross sectional area. [24].

\subsection{Coil Winding}

The arrangement of the copper winding should be designed well so that it is able to maximize the magnetic flux cutting and the efficiency of the generator itself. For the coreless electricity generator, coils of wire are used instead of multiple interconnected wires where the magnet rotates over them to produce the electricity. For instance, when the north pole of a magnet passing through a coil, the current flows in one direction, and when the South Pole passes over the coil, current flow through in the opposite direction.

Based on the theories, the most electricity is generated while the magnetic field is at 90 degrees to the coil winding and no electricity is generated when the magnetic field is parallel to the coil. [25]. The magnet 
that currently at the North Pole is pushing upward on the left radial leg of the coil. At the same time, the magnet that currently at the South Pole is pushing downward on the right radial leg. These two clockwise motions cause the electricity being generated. Notice that if both radial legs are pushing in the same direction. For example, left and right radial leg is pushing upward together at the same time, the motion cancels out each other, and thus, no electricity is generated. That is the reason that it is essential to arrange the magnet poles alternatively so that the motion will not cancels each other. The coil then connects to the three-phase power connection for maximum electricity output. To make pole pitch equal to the diameter of the coil, the thickness of the coil cannot increase more than $33 \%$ of pole pitch. It is because of geometrical relation, or simply say, the distance between coils must be equal to $133 \%$ of the pole pitch [25].

\subsection{Gaps between the Magnets}

The gap between magnets also a point needs to be taken care during the design of the coreless generator itself. If the gaps between them are further away, the efficiency of the generator cannot reach its full potential. If the gaps between them are too close, there is problem on placing the stator (copper coil winding) between them.

The optimum air gap size is calculated using Eq. 1, where $B_{m}$ represent maximum flux density in the air-gap, $\mathrm{g}$ represent the thickness of magnet, $\mu_{0}$ represent air permeability that can be calculated using Eq. 2, $\mathrm{B}_{\mathrm{r}}$ is for remanence, $H_{c}$ is for coercivity of magnet, $\delta$ represent airgap length, $\mathrm{H}$ is for external magnetic field strength and lastly for $\mathrm{m}$, it represent magnetic moment. [25]

$$
\begin{gathered}
\mu_{0}=4 \pi \cdot 10^{-7} \frac{H}{m} \\
B_{m}=\frac{2 g \mu_{0} B_{r} H_{c}}{B_{r} \delta+2 g \mu_{0} H_{c}}
\end{gathered}
$$

In Drazikowski Łukasz and Koczara Włodzimierz’s research model, their machine optimum air gap size is about $35 \mathrm{~mm}$. For the economic reason, they choose $33 \mathrm{~mm}$ as their preference air-gap because increasing airgap in between $33 \mathrm{~mm}$ to $38 \mathrm{~mm}$ has no significant influence on total output power.

\subsection{Summary}

The coreless electricity generator have different number of poles while some of them have a closer gap between rotors and different in size. To eliminate the cogging torque and the CEMF, ferrite material had to eliminate from the generator. For the coreless electricity generator, although the usage of the iron core is in minimum, still, it is not perfect to totally eleminate the cogging torque and CEMF still exist within the generator itself. To overcome such problems, ironless electricity generator configuration of the generator is a promising solution to be considered. Ironless electricity generator configuration has no core material or iron used in both rotor and stator. With the cogging torque eliminated, and CEMF is minimize and thus, less torque is require to spin.

\section{Analysis on the Ironless Electricity Generator}

JMAG, software that specialize in conducting electromagnetic analysis [26], is used in this study because of its specialization in the electromagnetic field. This software is capable of analyzing the electromechanical design such as Three-Phase Synchronous Generator [27]. From there, lots of parameter such as the number of turns of coil per phase and the type of magnet used can be specified. Optimization on the ironless electricity generator can be done once mastering the software.

\subsection{Analysis of the Changes of Number of Coil Turns}

This set of analysis is the open circuit method, which means there is no load on the circuit. The manipulated variable in this set of analysis is the number of coil turn per phase. Other variables like the material used on rotor and stator, grade of Neodymium magnet used and the rotational speed of rotor are kept constant. The effects of the coil turns per phase on the circuit voltage and magnetic flux within the coils can be clearly shown. Figure 1 shows the magnetic flux density contour plot for 500 turns per phase analysis while Figure 2 and Figure 3 displays the circuit voltage and magnetic flux within the coil respectively. In Table 1, it shows the comparison of the result gained. The voltage and magnetic flux within the circuit between the 500 coil turns, 1000 coil turns, 1500 coil turns and 2000 coil turns per phase are shown in Table 1. 


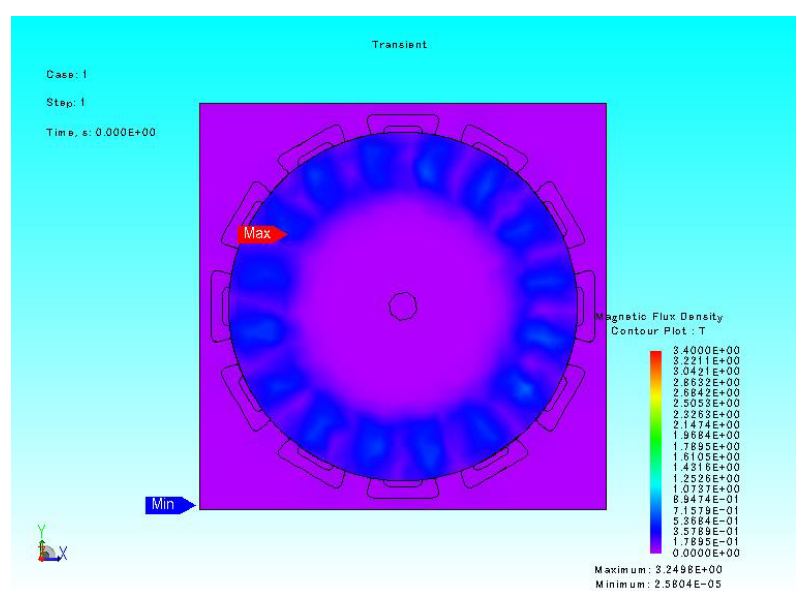

Figure 1. Magnetic flux density contour plot for 500 coil turns per phase analysis

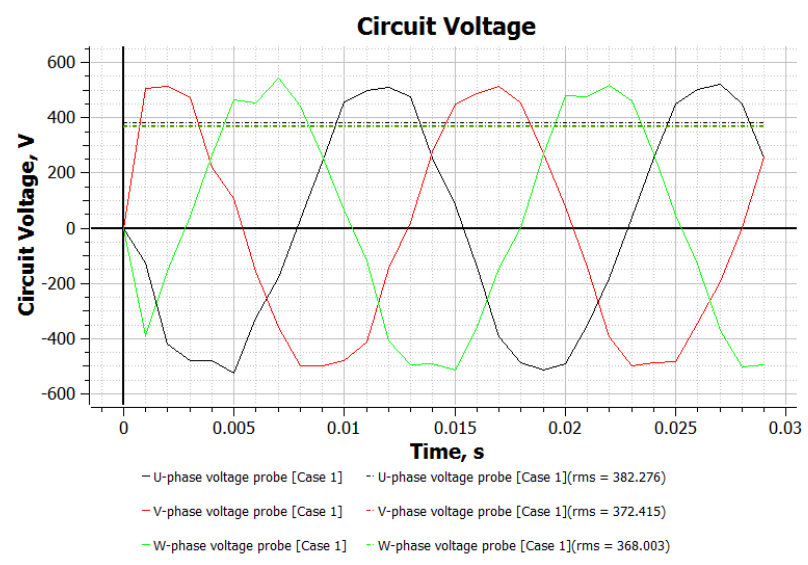

Figure 2. Circuit voltage for 500 coil turns per phase analysis

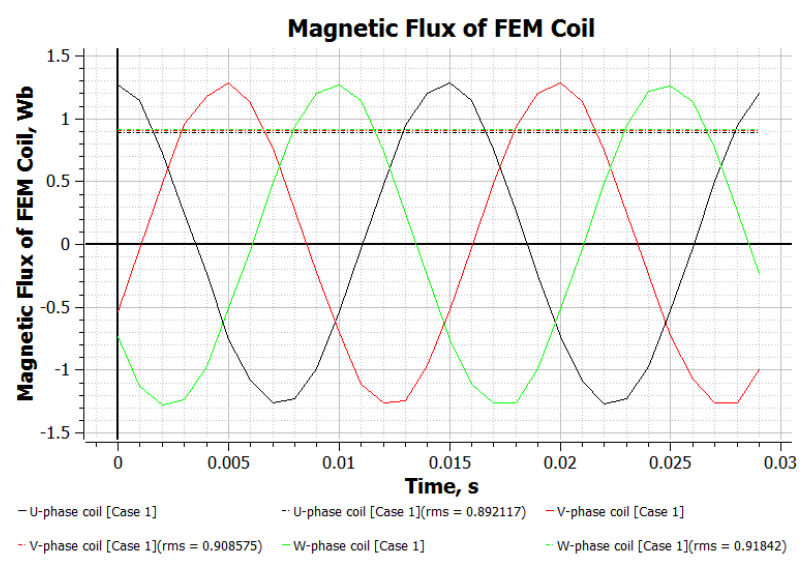

Figure 3. Magnetic flux within the coil for 500 coil turns per phase analysis
Table 1. Comparison between the number of coils turns per phase analysis

\begin{tabular}{|c|c|c|c|c|}
\hline & $\begin{array}{l}500 \text { coil } \\
\text { turns }\end{array}$ & $\begin{array}{l}1000 \text { coil } \\
\text { turns }\end{array}$ & $\begin{array}{l}1500 \text { coil } \\
\text { turns }\end{array}$ & $\begin{array}{c}2000 \text { coil } \\
\text { turns }\end{array}$ \\
\hline $\begin{array}{c}\text { Magnet } \\
\text { grade used }\end{array}$ & \multicolumn{4}{|c|}{ Grade N48 Neodymium Magnet } \\
\hline $\begin{array}{c}\text { U-phase } \\
\text { circuit } \\
\text { voltage } \\
\left(V_{\text {rms }}\right)\end{array}$ & 382.28 & 764.55 & 1146.83 & 1529.10 \\
\hline $\begin{array}{c}\text { V-phase } \\
\text { circuit } \\
\text { voltage } \\
\left(\mathrm{V}_{\mathrm{rms}}\right)\end{array}$ & 372.42 & 744.83 & 1117.24 & 1489.66 \\
\hline $\begin{array}{c}\text { W-phase } \\
\text { circuit } \\
\text { voltage } \\
\left(V_{\text {rms }}\right)\end{array}$ & 368.00 & 736.01 & 1104.01 & 1472.01 \\
\hline $\begin{array}{l}\text { Magnetic } \\
\text { flux in U- } \\
\text { phase coil } \\
\left(\mathbf{W b}_{\mathrm{rms}}\right)\end{array}$ & 0.89 & 1.78 & 2.68 & 3.57 \\
\hline $\begin{array}{l}\text { Magnetic } \\
\text { flux in V- } \\
\text { phase coil } \\
\left(\mathbf{W b}_{\text {rms }}\right)\end{array}$ & 0.91 & 1.82 & 2.73 & 3.63 \\
\hline $\begin{array}{l}\text { Magnetic } \\
\text { flux in W- } \\
\text { phase coil } \\
\left(\mathbf{W b}_{\mathrm{rms}}\right)\end{array}$ & 0.92 & 1.84 & 2.76 & 3.67 \\
\hline
\end{tabular}

\subsection{Analysis of the Magnetic Distance}

For the analysis of the gap distance between the magnetic pairs, the distance between the magnet pair is manipulated. In this analysis, it is using the open circuit configuration. Others parameter such as the material used on rotor and stator, magnet grade used and the number of coil turns per phase remain constant. There are total 5 different value of gap distance is analyzed with the distance between the magnet pairs of $12 \mathrm{~mm}, 14 \mathrm{~mm}$, $16 \mathrm{~mm}, 18 \mathrm{~mm}$, and $20 \mathrm{~mm}$ respectively.

For Figure 4, it shows the magnetic flux density contour plot for $20 \mathrm{~mm}$ magnet pairs distance simulation. Figure 5 shows the voltage within the circuit with the distance between the magnet pair of $20 \mathrm{~mm}$ while Figure 6 shows the magnetic flux within the circuit for the $20 \mathrm{~mm}$ distance between magnet pair analysis. Table 2 is the result comparison of different magnet pair distance. 


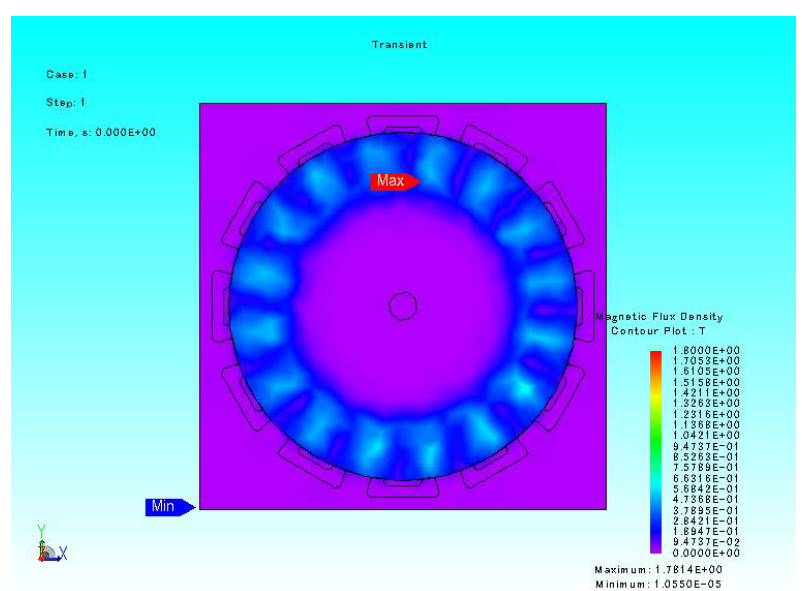

Figure 4. Magnetic flux density contour plot for magnet gap of $20 \mathrm{~mm}$ analysis

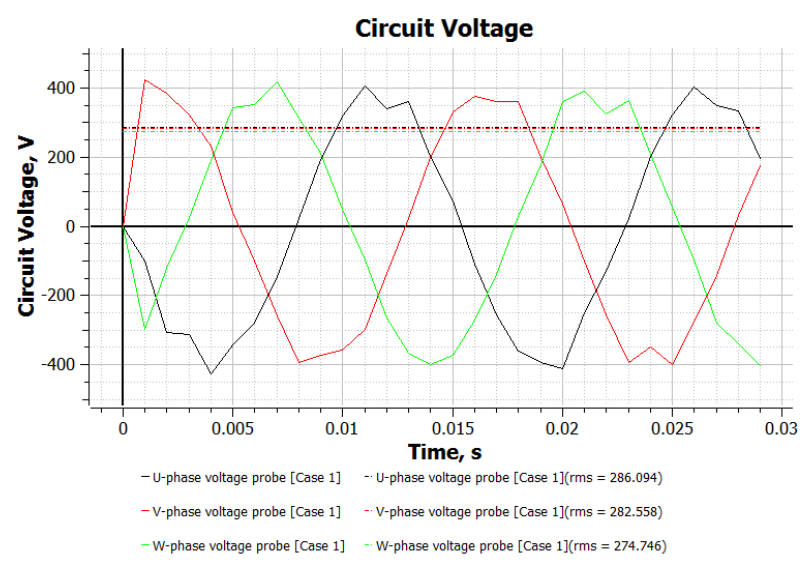

Figure 5. Circuit voltage for magnet gap of $20 \mathrm{~mm}$ analysis

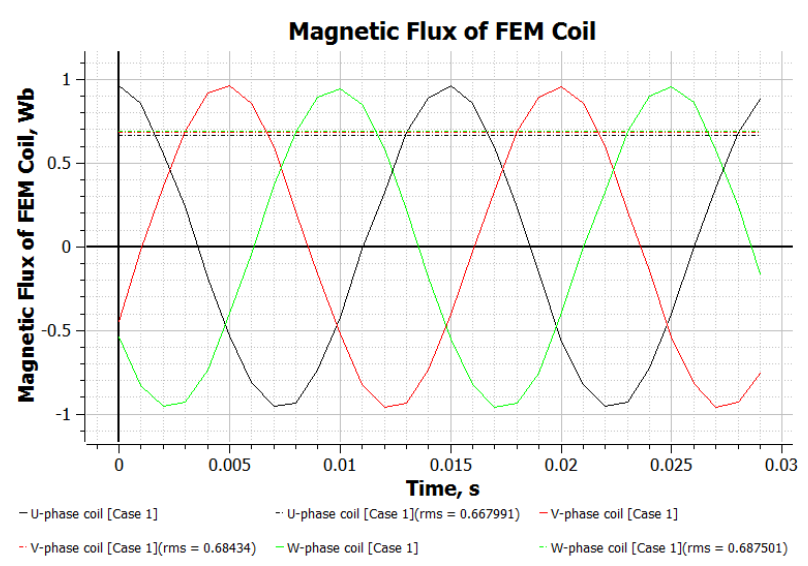

Figure 6. Magnetic Flux within the coil for magnet gap of $20 \mathrm{~mm}$ analysis
Table 2. Comparison between the various gap distances between the magnets analyzes

\begin{tabular}{cccccc}
\hline & $\mathbf{1 2 m m}$ & $\mathbf{1 4 m m}$ & $\mathbf{1 6 m m}$ & $\mathbf{1 8 m m}$ & $\mathbf{2 0 m m}$ \\
\hline $\begin{array}{c}\text { Magnet } \\
\text { grade } \\
\text { used }\end{array}$ & & Grade N48 Neodymium Magnet & \\
\hline $\begin{array}{c}\text { Coil turns } \\
\text { per phase }\end{array}$ & & & 500 & & \\
\hline $\begin{array}{c}\text { U-phase } \\
\text { circuit } \\
\text { voltage } \\
\text { (V) }\end{array}$ & 382.28 & 353.21 & 329.98 & 307.22 & 286.09 \\
\hline $\begin{array}{c}\text { V-phase } \\
\text { circuit } \\
\text { voltage } \\
\text { (V) }\end{array}$ & 372.42 & 345.63 & 323.00 & 301.67 & 282.56 \\
\hline $\begin{array}{c}\text { W-phase } \\
\text { circuit } \\
\text { voltage } \\
\text { (V) }\end{array}$ & 368.00 & 338.47 & 317.82 & 295.22 & 274.75 \\
\hline $\begin{array}{c}\text { Magnetic } \\
\text { flux in U- } \\
\text { phase coil } \\
\text { (Wb }\end{array}$ & 0.89 & 0.83 & 0.77 & 0.72 & 0.67 \\
\hline $\begin{array}{c}\text { Magnetic } \\
\text { flux in V- } \\
\text { phase coil } \\
\text { (Wb }\end{array}$ & 0.91 & 0.84 & 0.79 & 0.74 & 0.68 \\
\hline $\begin{array}{c}\text { Magnetic } \\
\text { flux in W- } \\
\text { phase coil } \\
\text { (Wb }\end{array}$ & 0.92 & 0.85 & 0.79 & 0.74 & 0.69 \\
\hline
\end{tabular}

\section{Discussion}

\subsection{Discussion on Different Number of Coil Turns per Phase}

When increasing the number of coil turns per phase, the result shows an increasing trend on voltage and magnetic flux within the coil. When increasing the number of coil turns per phase, it also increases the magnetic flux cutting rate, which cause the increasing of the voltage produced by the coil and magnetic flux in the coil as well. It is happening because with more turns of wire in the coil, the greater the strength of the static magnetic field around it. [28]

Refer to the Figure 7, the magnetic flux density within the design is concentrated. It is because the material used on rotor and stator is plastic, which means there is no reaction with the magnetic field. Thus, the magnetic flux is concentrated in the coil area. 


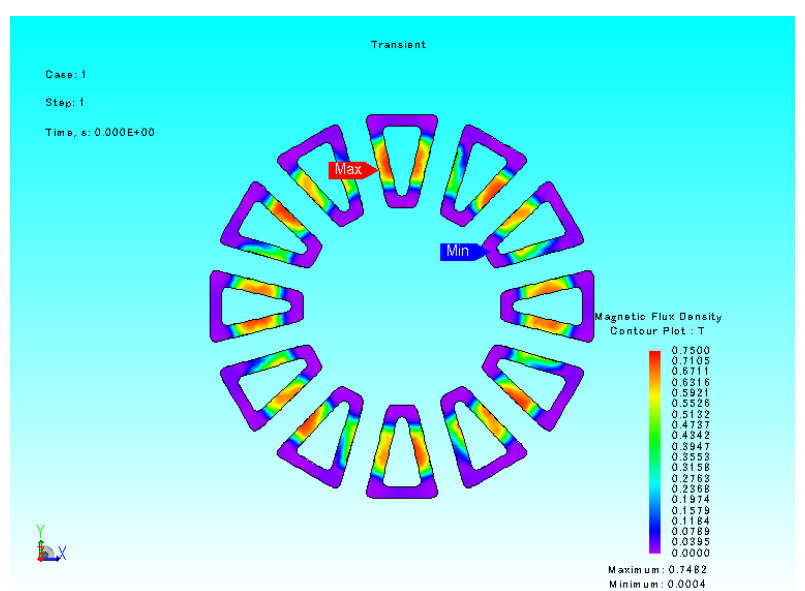

Figure 7. Magnetic flux concentrates on coil area

\subsection{Discussion on Distance between the Magnet Pairs}

When increasing the distance between the magnets pairs, the result shows a decreasing trend of voltage and magnetic flux within the coil. When increasing the distance between the magnets pair, the magnetic flux between the magnet decreases. With this, the magnetic flux cutting rate is decrease and thus, the voltage produced within the coil and the magnetic flux within the coil decrease. It is because the force acting between two magnetic poles is directly proportional to the product of their magnetic strength and inversely proportional to the square of the distance between the poles. [29]

\section{Conclusion}

Throughout the analysis, it can be concluded that the higher number of coil turns per phase, the higher voltage output and higher magnetic flux within the coil. For the gap between the magnet, it can be concluded that when the gap distance increase, the voltage produced by the coil and the magnetic flux within the coil decrease.

\section{References}

[1] Zhang, Z., Chen, A., Matveev, A., Nilssen, R., \& Nysveen, A. (2013). High-power generators for offshore wind turbines. Energy Procedia, 35, 52-61.

[2] Mahmoudi, A., Kahourzade, S., Rahim, N. A., Ping, H. W., \& Uddin, M. N. (2013). Design and prototyping of an optimized axial-flux permanentmagnet synchronous machine. IET Electric Power Applications, 7(5), 338-349.

[3] Gieras, J. F., Wang, R. J., \& Kamper, M. J. (2008). Axial flux permanent magnet brushless machines (Vol. 1). New York, NY: Springer.

[4] Mahmoudi, A., Rahim, N. A., \& Hew, W. P. (2011). Axial-flux permanent-magnet machine modeling, design, simulation, and analysis. Scientific Research and Essays, 6(12), 2525-2549.

[5] Ahmed D. and Ahmad A. (2013). An optimal design of coreless direct-drive axial flux permanent magnet generator for wind turbine. Journal of Physics: Conference Series 439 (2013) 012039

[6] Li, H., \& Chen, Z. (2008). Overview of different wind generator systems and their comparisons. IET Renewable Power Generation, 2(2), 123-138.

[7] Wang, R. J., Kamper, M. J., Van der Westhuizen, K., \& Gieras, J. F. (2005). Optimal design of a coreless stator axial flux permanent-magnet generator.Magnetics, IEEE Transactions on, 41(1), 55-64.

[8] Fitzgerald, A. E., \& Kingsley, C. (1961). Electric machinery: the dynamics and statics of electromechanical energy conversion. McGraw-Hill

[9] Virtic, P., Pisek, P., Marcic, T., Hadziselimovic, M., \& Stumberger, B. (2008). Analytical analysis of magnetic field and back electromotive force calculation of an axial-flux permanent magnet synchronous generator with coreless stator.Magnetics, IEEE Transactions on, 44(11), 4333-4336.

[10]Hwang, C. C., Li, P. L., Chuang, F. C., Liu, C. T., \& Huang, K. H. (2009). Optimization for reduction of torque ripple in an axial flux permanent magnet machine. Magnetics, IEEE Transactions on, 45(3), 1760-1763.

[11]Zhang, S., Tseng, K. J., Vilathgamuwa, D. M., Nguyen, T. D., \& Wang, X. Y. (2011). Design of a robust grid interface system for PMSG-based wind turbine generators. Industrial Electronics, IEEE Transactions on, 58(1), 316-328.

[12] Reggiani, U., Grandi, G., Sancineto, G., Serra, G. (2000). Comparison Between Air-Core and Laminated Iron-Core Inductors in Filtering Applications for Switching Converters. IEEE-CIEP Conference, Acapulco, (MEX), October 15-19, 2000

[13] Mirzaei, M., Mirsalim, M., \& Abdollahi, S. E. (2007). Analytical modeling of axial air gap solid rotor induction machines using a quasi-three-dimensional method. Magnetics, IEEE Transactions on, 43(7), 3237-3242.

[14]Del Ferraro, L., Giulii Capponi, F., Terrigi, R., Caricchi, F., \& Honorati, O. (2006, October). Ironless axial flux PM machine with active mechanical flux weakening for automotive applications. In Industry Applications Conference, 2006. 41st IAS Annual Meeting. Conference Record of the 2006 IEEE (Vol. 1, pp. 1-7). IEEE.

[15]Lombard, N. F., \& Kamper, M. J. (1999). Analysis and performance of an ironless stator axial flux PM machine. Energy Conversion, IEEE Transactions on, 14(4), 1051-1056.

[16] Breton, C., Bartolome, J., Benito, J. A., Tassinario, G., Flotats, I., Lu, C. W., \& Chalmers, B. J. (2000). Influence of machine symmetry on reduction of cogging torque in permanent-magnet brushless motors. Magnetics, IEEE Transactions on, 36(5), 3819-3823.

[17] Chen, J. L., \& Liu, T. H. (2012). Implementation of a predictive controller for a sensorless interior permanent-magnet synchronous motor drive system.Electric Power Applications, IET, 6(8), 513525 . 
[18] Hosseini, S. M., Agha-Mirsalim, M. \& Mirzaei, M. (2008). Design, Prototyping, and Analysis of a Low Cost Axial-Flux Coreless Permanent-Magnet Generator. IEEE Transaction on Magnetics, Vol. 44, No. 1, January 2008

[19] Javadi, S., \& Mirsalim, M. (2010). Design and analysis of $42-\mathrm{V}$ coreless axial-flux permanentmagnet generators for automotive applications. Magnetics, IEEE Transactions on, 46(4), 1015-1023.

[20] Kobayashi, H., Doi, Y., Miyata, K. and Minowa, T. (2009). Design of axial-flux permanent magnet coreless generator for the multi-megawatts wind turbines. EWEC2009.

[21]Bumby, J. R., \& Martin, R. (2005). Axial-flux permanent-magnet air-cored generator for smallscale wind turbines. IEE Proceedings-Electric Power Applications, 152(5), 1065-1075.

[22]Mo, W., Zhang, L., Shan, A., Cao, L., Wu, J., \& Komuro, M. (2008). Improvement of magnetic properties and corrosion resistance of $\mathrm{NdFeB}$ magnets by intergranular addition of MgO. Journal of Alloys and Compounds,461(1), 351-354.

[23]Chan, T. F., \& Lai, L. L. (2007). An axial-flux permanent-magnet synchronous generator for a direct-coupled wind-turbine system. Energy Conversion, IEEE Transactions on, 22(1), 86-94.

[24] K\&J Magnetics, Inc. Temperature and Neodymium Magnet. Retrieved from http://www.kjmagnetics.com/blog.asp?p=temperatur e-and-neodymium-magnets

[25] Drazikowski, L., \& Koczara, W. (2011). Permanent magnet disk generator with coreless windings. COMPEL: The International Journal for Computation and Mathematics in Electrical and Electronic Engineering, 31(1), 108-118.

[26]JMAG, Simulation Technologies for Electromechanical Design. Retrieved from https://jmag-international.com/

[27] Jenal, M., Sulaiman, E., Ahmad, M. Z., Zakaria, S. N. U., Utomo, W. M., Zulkifli, S. A., \& Bakar, A. A. (2013, November). Design study of single and threephase synchronous generator using J-MAG designer. In Clean Energy and Technology (CEAT), 2013 IEEE Conference on (pp. 226-231). IEEE.

[28] http://www.electronicstutorials.ws/electromagnetism/electromagneticinduction.html

[29] http://www.electrical4u.com/questions-and-answerson-magnet-field/ 